\title{
The role of caregivers in interfacility care transitions: a qualitative study
}

\author{
This article was published in the following Dove Press journal: \\ Patient Preference and Adherence \\ 21 August 2017 \\ Number of times this article has been viewed
}

\author{
Lianne Jeffs' \\ Marianne Saragosa' \\ Madelyn P Law ${ }^{2}$ \\ Kerry Kuluski ${ }^{3}$ \\ Sherry Espin ${ }^{4}$ \\ Jane Merkley ${ }^{5}$ \\ 'Keenan Research Centre of the \\ Li Ka Shing Knowledge Institute, \\ St Michael's Hospital, Toronto, \\ ${ }^{2}$ Department of Health Science, Brock \\ University, St Catharines, ${ }^{3}$ Lunenfeld- \\ Tanenbaum Research Institute, Sinai \\ Health System, ${ }^{4}$ Daphne Cockwell \\ School of Nursing, Ryerson University, \\ ${ }^{5}$ Executive Offices, Sinai Health \\ System, Toronto, ON, Canada
}

\begin{abstract}
A qualitative design was used to explore the nature of caregiver involvement in care transitions of patients being transferred from an acute care hospital to a rehabilitation hospital. Participants included older adults $(n=13)$, informal caregivers $(n=9)$, and health care professionals $(n=50)$ from inpatient orthopedic units in two academic health science centers and one orthopedic inpatient rehabilitation unit. Semistructured interviews were conducted, audiotaped, and transcribed. Directed content analysis revealed the following four themes: watching, being an active care provider, advocating, and navigating the health care system. Participants described being actively involved in the care of their family member, yet they were not actively engaged by health care professionals to be involved in the care of their family member. There is a need to reconcile the tension between the level of involvement of caregivers in the care of family members who are patients and the level of engagement throughout the care transition. By providing relevant information and authentically engaging caregivers as equal partners in the care transition, they are better able to navigate the health care system post-transfer to the rehabilitation setting and discharge to home.
\end{abstract}

Keywords: caregiver, care transitions, elderly, qualitative

\section{Introduction}

Older adults with complex medical conditions experience multiple care transitions involving different health care professionals across various care settings and systems of care. ${ }^{1}$ They are often at higher risk of experiencing inadequate care transitions as a result of not having a common care plan or being prepared for being discharged home and receiving conflicting self-management recommendations. ${ }^{2-5}$ Furthermore, poorer outcomes are associated with inadequate transitions, including an increased risk in the first 90 days post discharge for a return visit to the emergency department and readmission to the hospital, ${ }^{6}$ adverse medication events, ${ }^{7}$ functional decline, ${ }^{8}$ and patient and caregiver dissatisfaction. ${ }^{9}$

Patients and caregivers are the one constant in the care transitions process, and can provide valuable sources of information about the quality of care transitions and mitigate threats to patient safety and quality of care. ${ }^{8,10,11}$ For example, one study reported that older patients who had caregivers involved in the transition from hospital to home were significantly less likely to return to hospital than those who did not have caregiver involvement. ${ }^{10}$ However, caregivers are often not involved in discharge and care transition planning or processes. ${ }^{12-14}$ Furthermore, most studies on caregivers and care transitions have focused on older persons transitioning from acute care to home, ${ }^{12,15-18}$ with less known on how caregivers are involved in the care of their family member during interfacility care transitions (being transferred from an acute care hospital to an alternate level of care facility).
Correspondence: Lianne Jeffs

Li Ka Shing Knowledge Institute,

St Michael's Hospital, Room 720,

209 Victoria Street, Toronto,

ON M5B IT8, Canada

Tel +I 4I6864 6060 ext 77644

Email jeffsı@smh.ca
Patient Preference and Adherence 2017:I I |443-1450

(c) (1) ( \&) $\odot 2017$ Jefts et al. This work is published and licensed by Dove Medical Press Limited. The full terms of this license are available at https://www.dovepress.com/terms.php

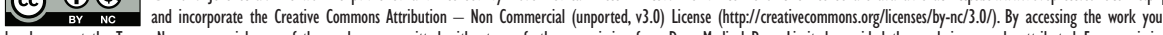
hereby accept the Terms. Non-commercial uses of the work are permitted without any further permission from Dove Medical Press Limited, provided the work is properly attributed. For permission for commercial use of this work, please see paragraphs 4.2 and 5 of our Terms (https://www.dovepress.com/terms.php). 
Given that care transitions are highly sensitive to variations in context, patients and their caregivers may have different experiences during interfacility care transitions. ${ }^{1,4}$ This is of particular importance for patients transferring from acute care to rehabilitation, where there is a shift in the focus of priorities from life and death to the return of function, health, and wellness. ${ }^{19}$ However, little is known about the level of engagement of patients and caregivers during this type of interfacility care transition. ${ }^{4}$ In this context, this study was undertaken with the aim of gaining insight into the nature of caregiver involvement in care transitions of patients being transferred from two acute care hospitals to a rehabilitation hospital.

\section{Subjects and methods Design}

An exploratory qualitative design was used to explore the perceptions and experiences associated with interfacility care transitions of nonelective patients aged $\geq 65$ years, caregivers, and health care providers. Ethics approval was obtained from the St. Michael's Hospital and Sinai Health System Research ethics boards.

\section{Setting and participants}

The study included orthopedic inpatient units situated in two acute care hospitals and one orthopedic unit at a complex continuing care rehabilitation facility in an urban community in Canada. Specifically, this study involved nonelective patients who had fallen or sustained a fracture though an accident and had first been admitted to an acute care orthopedic floor, then transferred to a 69 bed orthopedic unit that provides both high-intensity and reconditioning rehabilitation. The following inclusion criteria guided the recruitment of study participants: $\geq 65$ years, able to comprehend English and provide consent, and a nonelective orthopedic patient being transferred to a specific rehabilitation facility; caregivers were family members of the nonelective patient being transferred to a specific rehabilitation facility, were able to comprehend English and provide consent; and health care professionals were employed at the acute care hospital or rehabilitation facility, able to comprehend English, and provide consent. Written consent was obtained from all study participants prior to conducting the interviews.

\section{Data collection}

A purposeful sampling approach was used to recruit study participants. $^{20}$ This approach included the research assistant (RA) initially obtaining the names of potential patient participants based on the aforementioned inclusion criteria from clinical staff (nurse practitioner at hospital site 1 and a social worker at hospital site 2). For those who agreed to participate, the RA provided an overview of the study and obtained written consent from patients, which also included consent to contact their primary caregiver. The RA then approached the primary caregivers (in person if they were visiting the patient and/or by phone) and provided an overview of the study and obtained consent. Finally, the RA identified the health care professionals that provided care to the patient and approached them to participate in the study. The RA then provided an overview of the study and obtained consent from those health care professionals.

Interviews were conducted with study participants using open-ended interview guides developed from a "realist" literature review and Delphi panel. ${ }^{21}$ Through these initial phases, best practices for care transitions were identified. Engaging patients and their caregivers in care transition planning and processes emerged as a key strategy to ensure smooth care transitions and better care and outcomes for both patients and their caregivers. ${ }^{21}$ Key requests in the interview guide included: Describe your experience of the transition from the acute care hospital to the rehabilitation setting; Describe how you were involved in forming a care transition plan; Describe how you were involved in implementing the care transition plan; What was your preferred level of involvement in forming and implementing the care transition plan?; Describe how the nurse and/or members of the interprofessional care team informed you/provided education about your family member's care transition; Describe if and how you were made aware of any follow-up medical appointments, follow-up care, and a postdischarge plan; and What recommendations do you have to improve patient and caregiver experiences during inter-facility care transitions?

The interview guides were pilot-tested with the first few participants to ensure that they understood the questions being asked of them by the RA. Where possible, interviews were conducted face to face with patients and their caregivers shortly after the transfer from the acute care hospital to the rehabilitation facility and before being discharged home. In some cases, interviews were conducted separately and by phone. Interviews were conducted with the health care professionals in a private area in the hospital settings.

\section{Data analysis}

The transcribed interviews were analyzed using a directed content analysis approach ${ }^{22}$ and the consolidated criteria for reporting qualitative research. ${ }^{23}$ The transcripts were 
independently reviewed and coded as an initial step by the principal investigator and two RAs. The three then met and went through their respective codes on the transcripts to develop from consensus an initial coding schema. The codes were further collapsed into categories that were further refined into themes. The principal investigator created an audit trail, and as a final step reviewed all of the original transcripts with the emergent coding schema to ensure all codes and categories had been captured from the transcripts in the final coding schema. Strategies to ensure methodological rigor and saturation to be achieved included iterative analysis of the transcripts during the data collection period to enable emerging themes to be explored further in subsequent interviews, independent review of the transcripts and developing the coding schema by consensus, and constant comparison with the data. ${ }^{24}$

\section{Results}

\section{Participant characteristics}

Descriptive characteristics of the 72 participants are provided in Table 1. Of the 72 participants in the study, 15 patients were screened to participate in the interviews. Thirteen patients consented to participate, with two identified as ineligible, due to one patient demonstrating cognitive deficits and

Table I Demographic characteristics of patients, caregivers, and health care providers

\begin{tabular}{|c|c|c|c|}
\hline & Patients, $\mathrm{n}=13$ & Caregivers, $\mathbf{n = 9}$ & $\begin{array}{l}\text { Health care } \\
\text { providers, } n=50\end{array}$ \\
\hline Female, n (\%) & $9(69)$ & $9(100)$ & $39(78)$ \\
\hline Male, n (\%) & $4(3 I)$ & & II (22) \\
\hline Age (years), mean (range) & $82.9(68-91)$ & & \\
\hline \multicolumn{4}{|l|}{ Patient characteristics $(n=\mid 3)$} \\
\hline Comorbidities, average (range) & $5.4(2-16)$ & & \\
\hline Medications, average (range) & $8.5(5-17)$ & & \\
\hline \multicolumn{4}{|l|}{ Living arrangements, n (\%) } \\
\hline Lives alone & $12(92)$ & & \\
\hline Lives with spouse/partner & $\mathrm{I}(8)$ & & \\
\hline \multicolumn{4}{|l|}{ Caregiver characteristics $(n=9)$} \\
\hline \multicolumn{4}{|l|}{ Relationship to patient, n (\%) } \\
\hline Child & & $7(78)$ & \\
\hline Spouse/partner & & I (II) & \\
\hline Sibling & & I (II) & \\
\hline Duration of caregiver role (years), average (range) & & $63.1(51-89)$ & \\
\hline \multicolumn{4}{|l|}{ Health care provider characteristics $(n=50)$} \\
\hline \multicolumn{4}{|l|}{ Professional background, n (\%) } \\
\hline Nursing & & & $29(58)$ \\
\hline Physical therapy & & & $8(16)$ \\
\hline Pharmacy & & & $6(12)$ \\
\hline Social work & & & $3(6)$ \\
\hline Occupational therapy & & & $2(4)$ \\
\hline Medicine & & & I (2) \\
\hline Management & & & $I(2)$ \\
\hline \multicolumn{4}{|l|}{ Place of employment, n (\%) } \\
\hline Acute care & & & $26(52)$ \\
\hline Rehabilitation & & & $24(48)$ \\
\hline \multicolumn{4}{|l|}{ Years of experience } \\
\hline$<\mathrm{I}(\%)$ & & & $3(6)$ \\
\hline $2-5(\%)$ & & & $14(28)$ \\
\hline $6-10(\%)$ & & & $6(12)$ \\
\hline II-I5 (\%) & & & $12(24)$ \\
\hline$>16(\%)$ & & & $15(30)$ \\
\hline \multicolumn{4}{|l|}{ Employment status, n (\%) } \\
\hline Full-time & & & $39(78)$ \\
\hline Part-time & & & II (I2) \\
\hline \multicolumn{4}{|l|}{ Highest educational level, n (\%) } \\
\hline University & & & $24(48)$ \\
\hline Graduate school & & & $17(34)$ \\
\hline College & & & $9(18)$ \\
\hline
\end{tabular}


the other having been transferred to a different rehabilitation unit. Nine caregivers were approached to participate, and all consented. Health care providers involved in the transitional care of the 13 patients were also approached to be involved in the study. In total, 50 health care professionals consented and were involved in interviews.

\section{Themes}

Four themes were identified from the analysis: watching, being an active care provide, advocating, and navigating the health care system.

\section{Watching}

This theme reflects how caregivers actively participated by monitoring the care of their family members who were patients. Watching included the physical presence of the caregiver, usually at both the acute care and rehabilitation sites. Caregivers served a pivotal role in ensuring safe care transitions by being a "second pair of ears" (described by one participant as a second sober thought) to listen to what the various health care providers and administrators were saying about the patients. Some patients and several caregivers expressed concern that if they had not been present when health care providers were discussing the patient's status or care plan, then the patient would not have been able to understand what was said with regard to what was going on and to where they were being transferred. Caregivers also served as an "extra eye" by monitoring their family member. Caregivers were also watchful and alert to medication administration and changes in patients' status. Health care providers at both the acute care and rehabilitation hospitals observed the role of the caregiver of watching over their family member. This theme is illustrated in the following narrative excerpts:

If I hadn't been here and they were trying to give that information to my mother, it would have gone in one ear and out the other and she wouldn't have understood. [Caregiver, hospital site 1]

If I didn't have my daughter with her writing pad, writing everything down so that we could refer back to it, I wouldn't have had a clue. It was just too much happening. [Patient, hospital site 2]

I'm watching for that, and I think he's ready for a low dose now [wife commenting on her ensuring that her husband gets his medications for Parkinson's disease]. We're not expecting the same amount of nursing care here that he got there. I know he'll have to transition between being waited on and looking after himself a lot more.

[Caregiver, hospital site 2]

She is that extra eye that I find that has been very helpful when nurses might miss or not realize certain things, because she knows her husband the best. That's really how involved she is many of the times. [Nurse, hospital site 2]

\section{Being an active care provider}

This theme reflects the fact that some caregivers took on the responsibility for providing aspects of care that the health care providers and staff would normally do. For example, a mother (patient hospital site 1) described how her daughter has "... been looking after me like my own private nurse, and I don't think that that's fair or necessary". The daughter described how she has "been feeding her meals" and that staff come in and "they plunk the food down". This theme is echoed by a physiotherapist: “... family have to get a lot more involved if the patient can't do it themselves, because the resources aren't there." In one case, the caregiver stated that her administering medication was easier for her to do than the nurses, as they were experiencing challenges with the patient taking medication. With this particular patient, it was also noted by a physiotherapist that the caregiver's presence was helpful not only in providing care but also in decreasing the confusion of the patient. The following narrative excerpts elucidate this theme:

He's [patient's son] just been into everything. He brings me food every day and he talks to me about walking, about my chairs. I have to get up, and how I get up. [Patient, hospital site 1]

Because the nurses were on what seemed like an hourly schedule and they were a little bit frantic and they have other patients, they got used to leaving me, which was fine because I was there the whole time and I'm going to give them to him on time. It's a simple matter of getting him to put them [medication] in his mouth, and very often that was the problem because he didn't trust that nurse; he wouldn't swallow it. But he would take it from me, so it seemed easier for me. They would bring it, and I would dole it out. [Caregiver, hospital site 2]

It was good that his wife was present to help assist. I think that having family present helped a lot, especially with his confusion and just having someone there to help settle him in or get him in a wheelchair and then the wife was able to wheel him around. If she wasn't [present], I think he might have been more confused and he might have been more agitated. [Physiotherapist, rehabilitation hospital] 


\section{Advocating}

The theme reflected how caregiver participants were actively involved in advocating for their family member. Study participants were advocating for their family members' needs to be met, particularly concerning their mobility, functional status, physiotherapy services, and concerns about the patient being transferred to the rehabilitation facility or discharged home too early. Without caregiver advocacy, certain patient preferences may have been ignored and resulted in discomfort or harm to the patient. For example, one caregiver advocated for her mother, who was still experiencing pain from a fall and subsequent surgery. She did not want her mother to be moved from the ambulance stretcher to a temporary stretcher until the bed was ready at the rehabilitation facility. This caregiver further described her concerns: "If I hadn't been there on many of those occasions and really advocating for Mom, it wouldn't have happened." Patients also identified and valued how their family member advocated for them, to ensure their care needs were being met during the transitions. The following narratives provide examples of this theme:

My mother has it in her head that she may not be receiving it all [physiotherapy], but I've spoken to the nurse and the nurse assures me she has and she's going to receive some more today at 8:00. The sooner she gets into an intensive rehab place like [hospital $\mathrm{X}$ ], the better it will be for her, because then you'll assess how much independence she can have. That's the kind of discussion I think we'd like to have with the staff here at some point. If I don't hear anything, I'll probably be calling about it next week. [Caregiver, hospital site 1]

He was previously turned down for rehab, and they were thinking of just sending him to long-term care. But I dug my heels in, and I said he hadn't had enough physio and the reasons for not having enough physio were that his Parkinson's meds weren't given on time for him to be flexible enough for physio, and so physio backed off. I decided they cannot just ship him off without giving him a better chance at this physio. [Caregiver, hospital site 2]

When I did speak with the physiotherapist on the Monday, it was my suggestion that she get physiotherapy in home; they had not even applied for it. She hadn't done stairs yet either, and so that was my big concern and that's why I called [name]. I said, "She has stairs in her home and you're discharging her and she hasn't done stairs", so that's why I found it was premature. [Caregiver, hospital site 2]

She's been a very good advocate that way. Just anything, like, if she doesn't agree with something, she will mention it to a nurse or somebody, or me, you know?

[Patient hospital site 2]

\section{Navigating the health care system}

Closely aligned with the advocate role, caregivers also had to navigate the health care system, which included asking questions about and coordinating follow-up care. Caregivers were often asking questions on what was going to happen next, where their family member was going for rehabilitation, follow-up appointments, and how to coordinate services once their family member was discharged from the rehabilitation facility. Questions were often logistical in nature, as with one caregiver, who asked, "How does she get there?", knowing that her mother would not be able to get into the caregiver's car. Navigating the system often began when caregivers inquired about the different rehabilitation facilities. Caregivers were also active participants in coordinating care and services during and after hospitalization. Coordinating functions included arranging follow-up appointments with medical specialists, physiotherapy, transport, and coordinating community-based and home care services. For some caregivers, they also had to organize their family member's (patient) home to accommodate their mobility restrictions and postdischarge recovery. This became challenging when there was minimal communication by the health care team with caregivers about their family member's status and discharge plan from the rehabilitation facility. The following narratives illustrate this theme:

No, they don't really involve the family at all, and I think they really should, because the family, they take notes, they ask questions, they remember things. [Caregiver, hospital site 2]

There was no option of or any information of what these hospitals were. I remember asking, "Is one better than another for rehabilitation, specifically to the types of injuries that Mom has?", and everyone, the stock answer: "They're all good and they're all the same." Everything was on the fly that morning. I was saying to Mom I need to make that appointment. Do they make that appointment, do I phone for that appointment? [Caregiver, hospital site 2]

Then the social worker breezed in, and she [says], "It's great you're going home." A good portion of the getting-her-home part, we [family members] were the ones. My brother-in-law did all of the stuff to make her condo accessible for her, and that was an awful lot of work. I [arranged for] the meals, physio, and the home-care agency. [Caregiver, hospital site 2] 
Although I had to call, [community care organization] is the organization that provides the transport and the workers for my mother or the accompaniment when she has doctors' appointment, so I called them and I said my mother is in the hospital, could you suspend all of her services [home care-support services] because she has 5 hours a week now. [Caregiver, hospital site 1]

Because they're releasing her on a Friday, I asked for some assistance to arrange some care, and they said the social worker will get in touch with me; the social worker never did. Even the [home-care agency] case manager, she finally came in to see my mom but not until Thursday, and so I was trying to get in touch with her or him as well to arrange care and figure things out. Even today, [home-care agency] is supposed to call today and they haven't yet ... [Caregiver, hospital site 2]

She's got five or six appointments set up to go to different doctors over the next couple of months. I've just got to keep up with those and make sure I have all that stuff in place at all times. [Caregiver, hospital site 2]

\section{Discussion}

Caregivers were actively involved in the care of their family member, yet they were not actively engaged by health care professionals to be involved in the care of their family member. While this tension is described in another study of informal caregivers' active involvement in the care of their relative, yet struggling to gain influence, ${ }^{12}$ our study provides insight into the nature of this tension. Furthermore, patients, their caregivers, and the health care professionals acknowledged the role and importance of the caregivers during the care transition experiences.

In our study, the active involvement of caregivers included the need to be present and watch over their loved one to ensure their safety and well-being during their care transition experience. Caregivers shared how they ensured the right medications were provided at the right time, and some of the health care professionals expressed gratitude for the presence of family members and their ability to catch potential errors that otherwise might have been missed. Caregivers' experience of being present and watchful of their relative during the care transition episode is congruent with previous research findings. ${ }^{25,26}$ For example, one study described the vigilance of family members watching over loved ones who were dementia patients. ${ }^{25}$ Our study finding provides support for the integral role caregivers have in identifying harmful events that would remain otherwise undetected by health care professionals. ${ }^{27,28}$
The presence of caregivers in our study also included providing information about the patient to the health care professionals, and in turn interpreting the information provided by the health care team for their loved one. This role evoked frustration in some of the caregivers, as the health care professionals were often not available to answer questions on their loved one's care transitions plan (eg, Where are they going? Who do we connect with to arrange postdischarge care?). This finding is similar to other research, wherein patients and family members described as ineffective the communication between caregivers and health care professionals, as they waited for information and explanations on their transfer. ${ }^{4}$

Furthermore, some of the caregivers in our study were involved in providing direct care to their family member (eg, helping to feed them, administering medications, and conducting physical exercises). The presence of and active role of caregivers in providing care to their loved ones was often perceived by the caregiver and patient as being necessary to ensure appropriate and timely care was provided. For the health care professionals, the ability of the caregiver to provide aspects of patient care ensured that the patient would receive care required that might not have been provided, due to staff constraints and competing priorities. For example, a wife was able to provide additional physical therapy to her husband, who had suffered a hip fracture with an underlying diagnosis of Parkinson's disease. The provision of physical exercises was also reported, with caregivers providing physiotherapy to their family members who were patients to increase both therapy and patient adherence to physiotherapy. ${ }^{29}$ Increasingly, informal caregivers are being relied on as adjunct members of the health care team. ${ }^{26}$

Despite being actively involved with care, caregivers also had to advocate for the patient and their needs (eg, lack of information and preferences concerning care transition planning) and navigate the health care system during care transitions (eg, organizing postdischarge rehabilitation and community services) for their family member. Advocating for more information on their loved one's care plan is consistent with other studies that have demonstrated how caregivers must advocate for more information and involvement in care planning, in order to be prepared to support their relative after discharge home. ${ }^{12,18}$ Informal caregivers navigating the health care system and service delivery for older patients have been described in several studies. ${ }^{12,18,29,30}$

Interestingly, in our study, health care professionals did not engage in discussions with caregivers about their desired level of engagement in planning and implementing the 
care transitions plan, providing care to and watching over their family member, and navigating the health care system and advocating for their loved one. The caregivers took it upon themselves to be present and take an active role in their loved one transitioning from acute care to rehabilitation and preparing to be discharged home. This finding is similar to other work, wherein health care professionals described caregivers as being "indispensable intermediaries" during care transition ${ }^{12}$ and that family caregivers want to be involved to be able to arrange appropriate follow-up care for their loved one and to be prepared for the transition home. ${ }^{18}$

However, our finding that minimal discussion occurred on the caregiver's preferred level of engagement in the processes associated with care transitions warrants further attention. Failing to recognize caregivers' needs may have profound implications on their ability to support their family members through periods of transition. ${ }^{31,32}$ By providing relevant information and authentically engaging caregivers as equal partners in the care transition process, they are better able to discuss when information should be exchanged regarding the patient's recovery and care planning and navigate the health care system post-transfer to the rehabilitation setting and after discharge home. ${ }^{13}$

\section{Study limitations}

This study has the following three limitations. Caregivers involved were all female, which may present findings that do not reflect sex differences among informal caregivers of older adults. Our study is also limited by the inclusion of participants who were cognitively able to consent to participate in the interviews. Finally, this study involved only a small sample of patients and caregivers from orthopedic units, which may limit the transferability findings to patient populations with different medical conditions. However, the sample size was within the acceptable range to achieve thematic saturation. ${ }^{24}$

\section{Conclusion}

Our study results point to the need to reconcile the tension between the level of involvement of caregivers in the care of their family members and the level of engagement throughout the care transition process. The provision of direct care to patients by some of the caregivers in this study as a substitute for adequate staffing requires further attention. Future research should focus on reconciling these tensions and provide insight into how best to engage caregivers meaningfully and actively in the care transition planning of family members who are patients in the health care system.

\section{Acknowledgments}

This study was supported by a targeted nursing-research call from the Ontario Ministry of Health and Long-Term Care (grant 06693). LJ was supported by the St. Michael's Hospital Volunteer Association Chair in Nursing Research.

\section{Disclosure}

The authors report no conflicts of interest in this work.

\section{References}

1. Coleman E, Berenson RA. Lost in transition: challenges and opportunities for improving the quality of transitional care. Ann Intern Med. 2004;141:533-536.

2. Coleman E. Falling through the cracks: challenges and opportunities for improving transitional care for persons with continuous complex care needs. J Am Geriatr Soc. 2003;51:549-555.

3. Forster AJ, Murff HJ, Peterson JF, Gandhi TK, Bates DW. The incidence and severity of adverse events affecting patients after discharge from the hospital. Ann Intern Med. 2003;138:161-167.

4. Jeffs L, Kitto S, Merkley J, Lyons RF, Bell CM. Safety threats and opportunities to improve interfacility care transitions: insights from patients and family members. Patient Prefer Adherence. 2012;6:711-718.

5. Dykes PC, Samal L, Donahue M, et al. A patient-centered longitudinal care plan: vision versus reality. $J$ Am Med Inform Assoc. 2014;21:1082-1090.

6. Aminzadeh F, Dalziel WB. Older adults in the emergency department: a systematic review of patterns of use, adverse outcomes, and effectiveness of interventions. Ann Emerg Med. 2002;39:238-247.

7. Coleman E, Smith JD, Raha D, Min SJ. Posthospital medication discrepancies: prevalence and contributing factors. Arch Intern Med. 2005; 165:1842-1847.

8. Rowland K, Maitra AK, Richardson DA, Hudson K, Woodhouse KW. The discharge of elderly patients from an accident and emergency department: functional changes and risk of readmission. Age Ageing. 1990;19:415-418.

9. Toscan J, Manderson B, Santi S, Stolee P. "Just another fish in the pond": the transitional care experience of a hip fracture patient. Int $J$ Integr Care. 2013;13:e023.

10. Coleman E, Smith JD, Frank JC, Min SJ, Parry C, Kramer AM. Preparing patients and caregivers to participate in care delivered across settings: the care transitions intervention. J Am Geriatr Soc. 2004;52:1817-1825.

11. Geerlings SW, Pot AM, Twisk JW, Deeg DJ. Predicting transitions in the use of informal and professional care by older adults. Aging Soc. 2005;25:111-130.

12. Bragstad LK, Kirkevold M, Foss C. The indispensable intermediaries: a qualitative study of informal caregivers' struggle to achieve influence at and after hospital discharge. BMC Health Serv Res. 2014;14:331.

13. Bull MJ, Hansen HE, Gross CR. Differences in family caregiver outcomes by their level of involvement in discharge planning. Appl Nurs Res. 2000;13:76-82.

14. Digby R, Moss C, Bloomer M. Transferring from an acute hospital and settling into a subacute facility: the experience of patients with dementia. Int J Older People Nurs. 2012;7:57-64.

15. Dossa A, Bokhour B, Hoenig H. Care transitions from the hospital to home for patients with mobility impairments: patient and family caregiver experiences. Rehabil Nurs. 2012;37:277-285.

16. Ford BK, Ingersoll-Dayton B, Burgio K. Care transition experiences of older veterans and their caregivers. Health Soc Work. 2016;41:129-138.

17. Giosa JL, Stolee P, Dupuis SL, Mock SE, Santi SM. An examination of family caregiver experiences during care transitions of older adults. Can J Aging. 2014;33:137-153.

18. Hvalvik S, Reierson IA. Striving to maintain a dignified life for the patient in transition: next of kin's experiences during the transition process of an older person in transition from hospital to home. Int $J$ Qual Stud Health Well-Being. 2015;10:26554. 
19. Tardif G, Baker GR, Fancott C, et al. Partnering with patients and families to balance safety and autonomy. 2009. Canadian Patient Safety Institute. Edmonton, Alberta.

20. Patton MQ. Qualitative Research and Evaluation Methods. 3rd ed. Thousand Oaks (CA): Sage; 2001.

21. Jeffs L, Kuluski K, Law M, et al. Identifying effective nurse-led care transition interventions for older adults with complex needs using a structured expert panel. Worldviews Evid Based Nurs. 2017;14: 136-144.

22. Hsieh HF, Shannon SE. Three approaches to qualitative content analysis. Qual Health Res. 2005;15:1277-1288.

23. Tong A, Sainsbury P, Craig J. Consolidated criteria for reporting qualitative research (COREQ): a 32-item checklist for interviews and focus groups. Int J Qual Health Care. 2007;19:349-357.

24. Morse JM. The significance of saturation. Qual Health Res. 1995;5: $147-149$.

25. Strang VR, Koop PM, Dupuis-Blanchard S, Nordstrom M, Thompson B. Family caregivers and transition to long-term care. Clin Nurs Res. 2006; $15: 27-45$
26. Van Houtven $\mathrm{CH}$, Norton EC. Informal care and health care use of older adults. J Health Econ. 2004;23:1159-1180.

27. Vincent $\mathrm{C}$, Davis R. Patients and families as safety experts. CMAJ. 2012;184:15-16.

28. Iedema R, Allen S, Britton K, Gallagher TH. What do patients and relatives know about problems and failures in care? BMJ Qual Saf. 2012;21: 198-205.

29. Byrne K, Orange JB, Ward-Griffin C. Care transition experiences of spousal caregivers: from a geriatric rehabilitation unit to home. Qual Health Res. 2011;21:1371-1387.

30. Levine C, Halper D, Peist A, Gould DA. Bridging troubled waters: family caregivers, transitions, and long-term care. Health Aff (Millwood). 2010;29:116-124.

31. Ghazzawi A, Kuziemsky C, O’Sullivan T. Using a complex adaptive system lens to understand family caregiving experiences navigating the stroke rehabilitation system. BMC Health Serv Res. 2016;16:538.

32. Davis RE, Sevdalis N, Jacklin R, Vincent CA. An examination of opportunities for the active patient in improving patient safety. $J$ Patient Saf. 2012;8:36-43.

\section{Publish your work in this journal}

Patient Preference and Adherence is an international, peer-reviewed, open access journal that focuses on the growing importance of patient preference and adherence throughout the therapeutic continuum. Patient satisfaction, acceptability, quality of life, compliance, persistence and their role in developing new therapeutic modalities and compounds to optimize clinical outcomes for existing disease states are major areas of interest for the journal. This journal has been accepted for indexing on PubMed Central. The manuscript management system is completely online and includes a very quick and fair peer-review system, which is all easy to use. Visit http://www. dovepress.com/testimonials.php to read real quotes from published authors. 